\title{
VARIATIONS IN BIRD POPULATIONS IN A BROAD LEAFED WOODLAND: 1975 TO 1998
}

\author{
I. SIMMS ${ }^{1} *-$ J.R. SIMMS - A. CHARLETT ${ }^{2}-$ N.J. ANDREWS ${ }^{2}$ \\ ${ }^{1}$ Health Protection Agency Centre for Infections \\ ${ }^{2}$ Health Protection Agency, Statistics, Modelling and Bioinformatics Department 61 Colindale \\ Avenue, London, United Kingdom NW9 5EQ \\ (phone: +44-(0)208-327-7571; fax: +44-(0)208-200-7868) \\ *Corresponding author \\ e-mail:ian.simms@hpa.org.uk \\ (Received $10^{\text {th }}$ April 2008 ; accepted $6^{\text {th }}$ July 2009)
}

\begin{abstract}
Variations in passerine populations were examined at a single Common Bird Census location over 24 years. Long term trends in the populations of Robin Erithacus rubecula, Blackbird Turdus merula, Wren Troglodytes troglodytes, Blue Tit Parus caeruleus and Great Tit Parus major were investigated. The statistical method proposed by Bulmer[1], which overcomes the problem of regressions to the mean, was used to investigate density-dependent variation (DDV). Little evidence of DDV was found and so long-term population trends could be evaluated. The commonest species seen were the Wren and Robin. Significant increases were seen in breeding pairs of Great Tit $(\mathrm{p}=<0.001)$ and Wren $(\mathrm{p}=0.048)$ whereas those of Blackbird decreased $(\mathrm{p}=0.006)$ and there was no significant change in breeding pairs of Blue Tit $(\mathrm{p}=0.090)$ or Robin $(\mathrm{p}=0.871)$. Selection pressures on the populations studied were probably reduced by the consistently mild winters and feeding at bird tables in the gardens near the study area in winter. The $\mathrm{CBC}$ technique is recognised as the most accurate method of estimating the size of breeding bird populations. This analysis shows that the $\mathrm{CBC}$ data collection method, combined with relatively simple statistical techniques, can be used to accurately interpret local trends in breeding bird populations.
\end{abstract}

Keywords: Bird Census, density-dependent variation

\section{Introduction}

In 1962 the British Trust for Ornithology (BTO) instigated the Common Bird Census (CBC) to monitor trends in bird populations[2]. National analyses may mask trends within local populations, including density-dependent variation (DDV). Since many CBC sites have been surveyed for over 20 years they are ideal for investigating local variations within breeding bird populations. This analysis evaluated variations in passerine populations at one such CBC location in Hampshire, UK.

\section{Materials and methods}

Southampton Common (147 ha) lies within the city suburbs and is surrounded by suburban gardens. The 57 ha study area in the Common's northwest corner consisted of open parkland, heathland and mature mixed woodland growing on Bracklesham Beds, a combination of pale yellow sands and dark mottled clay. The Common was used for animal grazing until the 1930s and consequently the ground flora is impoverished, the herb layer dominated by Bracken Pteridium equilimum and Bramble Rubus fruticosus. Open grassland covered a third of the study area. Clumps of woodland consisted of a canopy dominated by Oak Quercus robur and Birch Betula spp with an understorey of 
Holly Ilex aquifolium and Hawthorn Crataegus monogyna. In 1975, the study area was isolated from the rest of the Common but over the course of the survey vegetation grew over the boundary paths and the territories of some breeding pairs overlapped adjacent areas of the Common. Management and successional change were small, trees were pruned only when dangerous, grass was cut after the ground flora had seeded, and neither herbicides nor pesticides were used. Nest boxes were not provided and holenesting species were restricted to natural tree cavities. The main predators were Sparrowhawk Accipiter nisus, Magpie Pica pica, Squirrel Sciurus carolinesis, and Rat Rattus norveigicus. From 1980, a pair of Sparrowhawks nested in or near the study area. Between 1975 and 1990, there were an average of 3 pairs of Magpies within the study areas but this rose to an average of 7.5 pairs between 1991 and 1998. Traps were used to control the rat population.

Measurement error is a problem in any study that uses time trend data but was minimised here as all data were collected and interpreted for the CBC[3] by the same observer (J.R. Simms) who used a consistent observational technique. All data were collected during fine weather either in the morning or, less frequently, early evening. Data were analysed by the BTO[2] to estimate the annual number of singing males. Over the study period 39 species were recorded but this analysis was restricted to those with a mean number of breeding pairs of over 10 per annum: Robin Erithacus rubecula, Blackbird Turdus merula, Wren Troglodytes troglodytes, Blue Tit Parus caeruleus and Great Tit Parus major (Fig. 1). Temperature $\left({ }^{\circ} \mathrm{C}\right)$, rainfall and snowlie data were obtained from a weather station four miles away on the coast (Fig. 2). Mean winter temperature was calculated for each year by taking the mean of the monthly means for the six month consecutive period between October and March inclusive, calculated as the average of the monthly mean maxima and minim.

Multivariable linear regression was used to explore the relationship between the number of breeding pairs of each species, and the mean winter temperature, mean winter rainfall and mean snowfall[4]. The influence of DDV on the number and change in breeding pairs is difficult to analyse because of regression to the mean. For example, even in a series of random numbers, the correlation between the numbers in the series and the change between consecutive numbers is 0.7. To overcome these problems, the methods described by Bulmer[1] was used to test for DDV. Bulmer suggested that a test for DDV could be calculated in two ways which he described as $R$ and $R^{*} . R$ is the ratio of $V$ (the sum of squares of $\log$ densities about the mean $\log$ density) and $U$ (the sum of squares of change in log densities): the smaller the ratio, the greater the difference from the mean. Bulmer suggested that measurement error would decrease $R$, a problem that was recognised in $R^{*} . R^{*}$ is the ratio of $W$ (the sum of log densities about the mean log density multiplied by the change in log densities between the next two log densities in the series) and $V$. DDV will tend to decrease $R^{*}$. Values of $R<1.0552$ and $\mathrm{R}^{*}<-0.373$ indicate evidence of DDV at the $5 \%$ level. The power of $R^{*}$ is lower than $R$ and consequently false negative results may occur in sample sizes of less than 25 . Here values for $R$ and $R^{*}$ were calculated for each species and the results are shown for comparative purposes. We considered that $\mathrm{R}^{*}$ was a better measure to use within this dataset. Poisson regression was used to investigate trends in breeding pairs over time. 


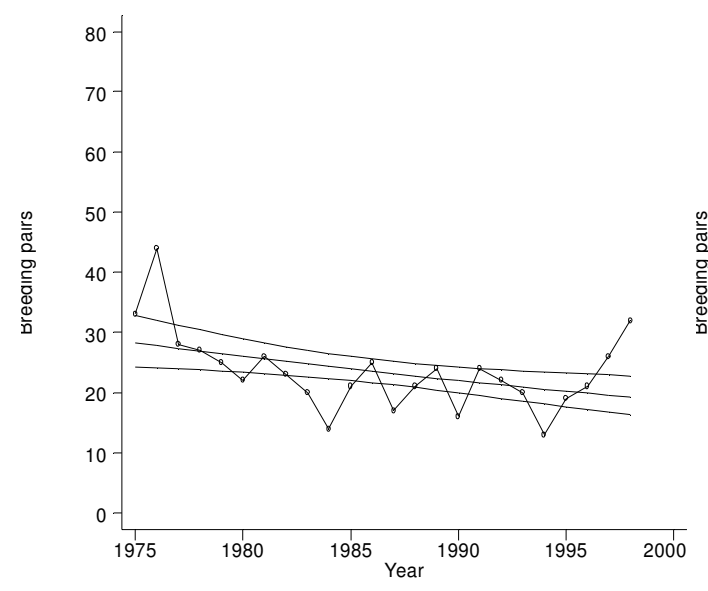

(i) Blackbird

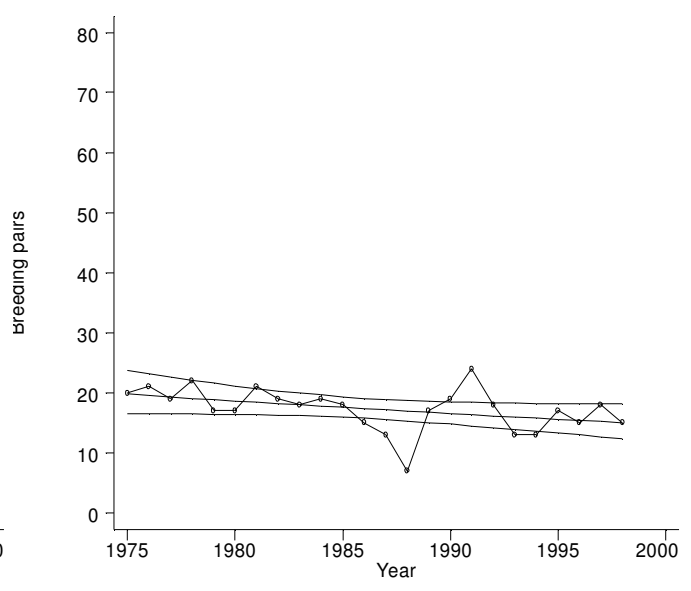

(ii) Blue Tit

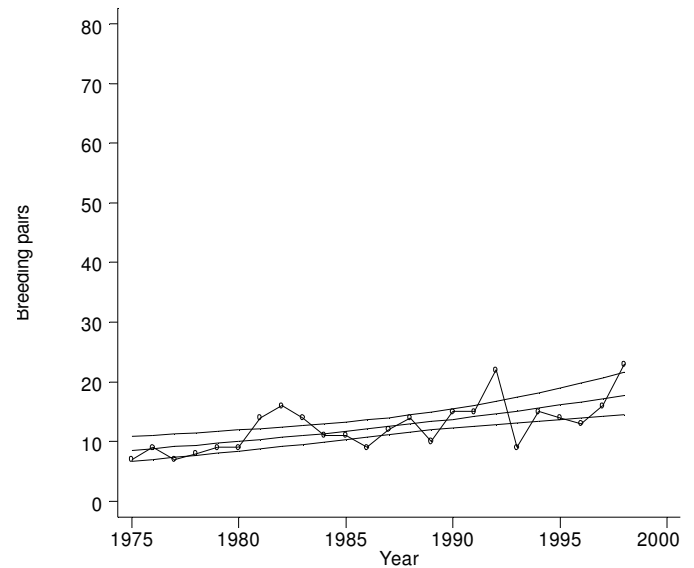

(iii) Great Tit

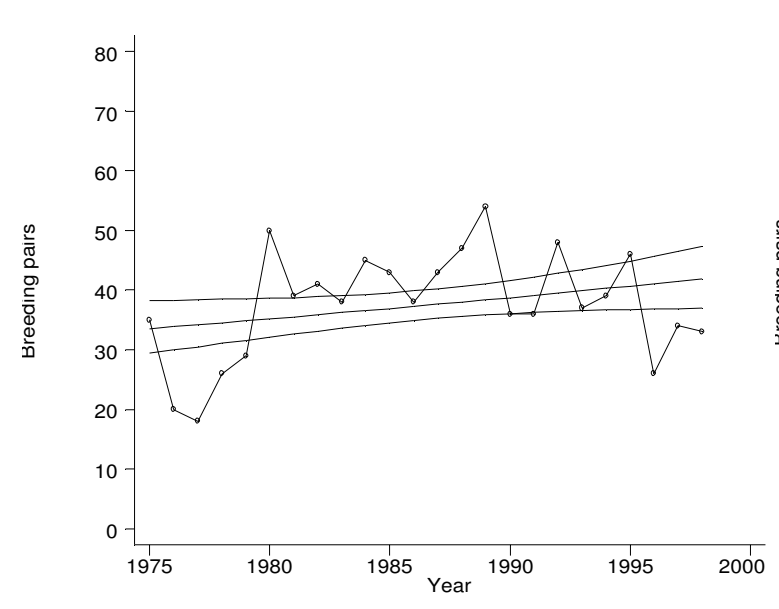

(iv) Wren

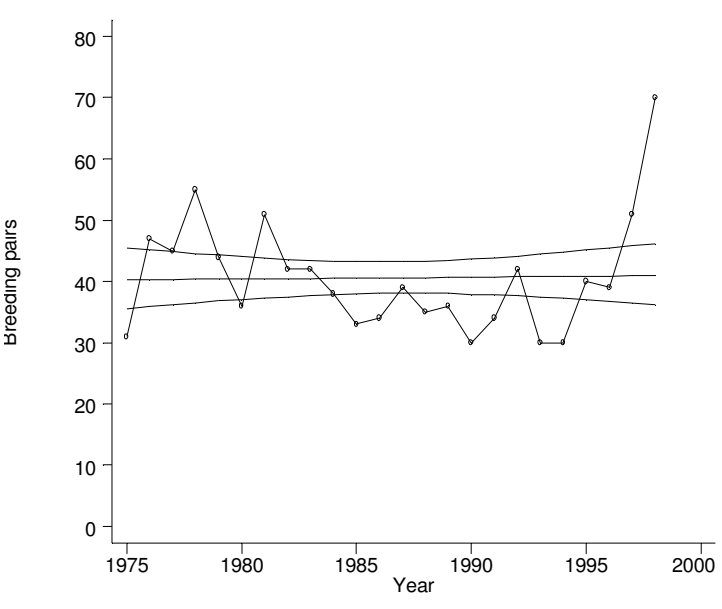

(v) Robin

Figure 1. Numbers of singing males, regression coefficient and 95\% confidence limits: 1975 to 1998 


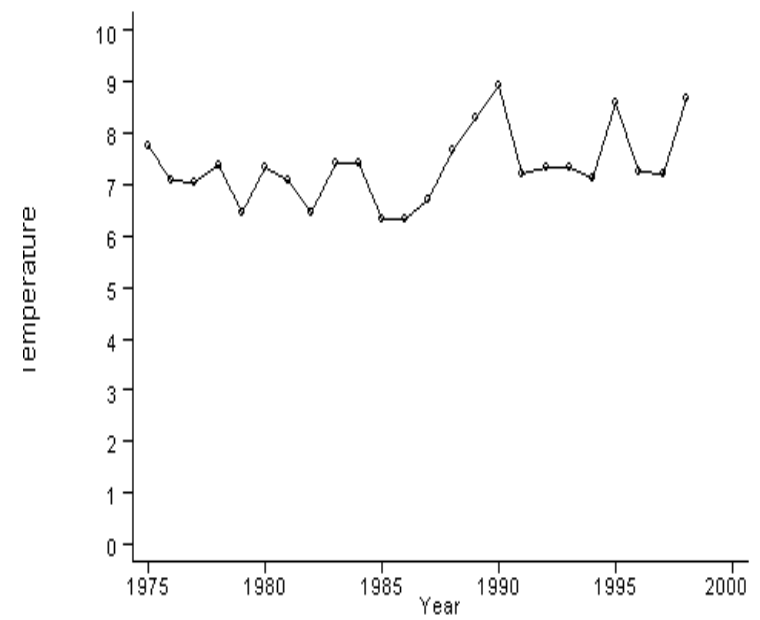

(i) Temperature $\left({ }^{\circ} \mathrm{C}\right)$



(ii) Rainfall (cm)

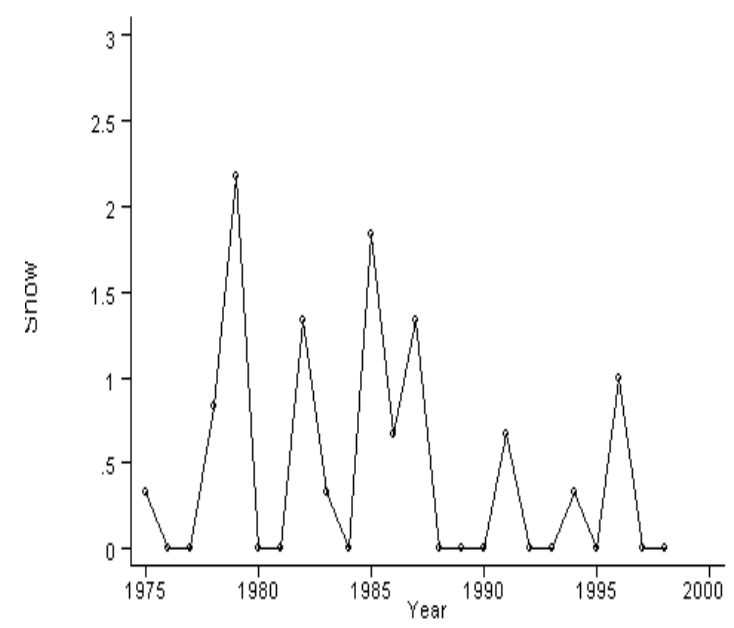

(iii) Snowlie $(\mathrm{cm})$

Figure 2. Mean winter temperature $\left({ }^{\circ} \mathrm{C}\right)$, rainfall $(\mathrm{cm})$ and snowlie $(\mathrm{cm}): 1975$ to 1998

\section{Results}

Over the 24 years, 853 breeding pairs of Robin (mean per annum 39), 505 of Blackbird (mean/annum $=23), 853$ of Wren (mean/annum $=38$ pairs), 383 of Blue Tit (mean/annum $=17$ pairs) and 263 of Great Tit (mean/annum $=12$ pairs) were seen in the study area.

There was no evidence of an association between any of the species studied and the environmental factors using multivariable regression, except between Blackbird and rainfall $(\mathrm{p}=0.028)$. These results are shown in Table 1 . The $R$ values for each species were: Robin (1.045), Blackbird (0.991), Wren (1.035), Blue Tit (0.785) and Great Tit (1.066). The $R$ values for the Robin, Blackbird, Wren and Blue Tit were significant at the $5 \%$ level (1.0552). The $R^{*}$ values were: Robin $(-0.088)$, Blackbird (-0.2551), Wren $(-0.2438)$, Blue Tit $(-0.334)$ and Great Tit (0.0214). These values were not significant at the 5\% level (-0.373), although the value for the Blue Tit was bordering on significance.

Breeding pairs of the Great Tits increased by $3.2 \%$, a significant increase over time $(\mathrm{p}=<0.001$ : rate ratio per year $=1.032,95 \%$ confidence limit 1.015 to 1.049 ; a $3.2 \%$ increase per year). There was also a significant increase in breeding pairs of the Wren 
( $\mathrm{p}=0.048$ : RR 1.009, 95\% CL 1.000 to 1.019), whereas there was a significant decrease in the Blackbird ( $\mathrm{p}=0.006$ : RR 0.983, 95\% CL 0.971 to 0.995) (Fig. 1). No significant variation was seen for the Blue Tit ( $\mathrm{p}=0.090$ : RR 0.988, 95\% CL 0.974 to 1.001) or Robin ( $\mathrm{p}=0.871$ : RR 1.000, 95\% CL 0.991 to 1.009 ).

Table 1. Results of two-way regression analysis

\begin{tabular}{|c|c|c|c|c|c|c|}
\hline \multirow[b]{2}{*}{ Species } & \multicolumn{6}{|c|}{ Weather variable } \\
\hline & $\begin{array}{c}\text { Temperature } \\
\text { Regression } \\
\text { coefficient } \\
\left(\text { per }^{\circ} \mathrm{C} \text { of }\right. \\
\text { average temp) } \\
(95 \% \mathrm{CL})\end{array}$ & $p$ value & $\begin{array}{c}\text { Rainfall } \\
\text { Regression } \\
\text { coefficient } \\
\text { (per cm average } \\
\text { rainfall) } \\
(95 \% \mathrm{CL})\end{array}$ & $p$ value & $\begin{array}{c}\text { Snowlie } \\
\text { Regression } \\
\text { coefficient } \\
\text { (per cm average } \\
\text { snowlie) } \\
(95 \% \text { CL) }\end{array}$ & $p$ value \\
\hline Robin & $\begin{array}{c}1.594 \\
(-4.225 \text { to } 7.413)\end{array}$ & 0.576 & $\begin{array}{c}-0.068 \\
(-0.271 \text { to } 0.134)\end{array}$ & 0.493 & $\begin{array}{c}-1.174 \\
(-7.566 \text { to } 5.217)\end{array}$ & 0.707 \\
\hline $\begin{array}{l}\text { Blackbi } \\
\text { rd }\end{array}$ & $\begin{array}{c}-0.437 \\
(-4.551 \text { to } 3.676)\end{array}$ & 0.828 & $\begin{array}{c}-0.146 \\
(-0.275 \text { to }-0.017)\end{array}$ & 0.028 & $\begin{array}{c}-1.029 \\
(-5.512 \text { to } 3.452)\end{array}$ & 0.638 \\
\hline Wren & $\begin{array}{c}2.342 \\
(-3.242 \text { to } 7.927)\end{array}$ & 0.394 & $\begin{array}{c}-0.038 \\
(-0.236 \text { to } 0.159)\end{array}$ & 0.693 & $\begin{array}{c}-1.945 \\
(-8.099 \text { to } 4.207)\end{array}$ & 0.519 \\
\hline Blue Tit & $\begin{array}{c}-0.179 \\
(-2.407 \text { to } 2.048)\end{array}$ & 0.869 & $\begin{array}{c}-0.056 \\
(-0.130 \text { to } 0.017)\end{array}$ & 0.126 & $\begin{array}{c}0.157 \\
(-2.280 \text { to } 2.594)\end{array}$ & 0.895 \\
\hline $\begin{array}{l}\text { Great } \\
\text { Tit }\end{array}$ & $\begin{array}{c}1.875 \\
(-0.614 \text { to } 4.364)\end{array}$ & 0.133 & $\begin{array}{c}-0.005 \\
(-0.096 \text { to } 0.086)\end{array}$ & 0.910 & $\begin{array}{c}-1.209 \\
(-4.029 \text { to } 1.610)\end{array}$ & 0.383 \\
\hline
\end{tabular}

\section{Discussion}

This study examined variations in passerine populations at a single $\mathrm{CBC}$ location over 24 years. No evidence of DDV was found in the Robin, Blackbird and Wren using the $\mathrm{R}^{*}$ statistic and borderline evidence of DDV was seen for the Blue Tit. Other English studies that investigated trends in passerine breeding pairs in similar habitats reported evidence of DDV in the same species as studied here[5], and clutch size, hatching success and territorial behaviour[6]. A national analysis of CBC data also found evidence of DDV in passerines within woodland sites[7]. The fact that DDV was not detected here was not due to a type I statistical error as the tests used were capable to detecting DDV within these types of data. Rather selection pressures on the species studied could have been reduced by feeding at bird tables in the gardens near the Common in winter, and the consistently mild winters of the local maritime climate. Potential sources of bias, including habitat change, predation and the concentration of singing and other conspicuous activities on dry days in wet years[7], are likely to be minimal as they promote DDV.

The absence of DDV allowed an opportunity to evaluate long-term trends in breeding pairs. The commonest species seen were the Wren and Robin. Although there was a considerable fluctuation from year to year, there was a significant increase in the Wren population over the study period in line with national and European trends[8]. Since Wrens do not generally feed at bird tables their populations are sensitive to hard winters[9]. Here this selection pressure was probably reduced by the consistently mild winters. There was no significant variation in the Robin population compared to the overall rise seen in the UK and many parts of Europe[8]. The significant decline in breeding pairs of Blackbirds mirrors the shallow decline seen in the national CBC records since the 1970s. Breeding pairs of Great Tits increased in line with the national 
trend seen since the late 1960's, but there was no significant variation in the number of Blue Tits in contrast to the shallow increase seen nationally over the same period[8]. Feeding at bird tables during the winter is known to reduce DDV[10] and Robins, Blackbirds, Blue Tits and Great Tits feed in the gardens near the Common in winter which may explain the increases in breeding pairs. However, the decline in the Blackbird over the same period has been attributed to reduced survival of adults and juveniles[11]. It is likely that other factors which were not measured in this analysis, such as nutrition, clutch size and survival, influenced the populations studied and reduced the sensitivity of the investigation. Whilst their inclusion would have allowed a more detailed exploration of the variation in population density, the study would have been much more time consuming and resource intensive.

The CBC technique is recognised as the most accurate method of estimating the size of breeding bird populations. This analysis shows that this data collection method combined with relatively simple statistical techniques can be used to accurately interpret local trends in the populations of breeding birds.

Acknowledgements. We would like to thank Dr Peter Rothery, Institute of Terrestrial Ecology, for his helpful comments on an earlier draft, and the UK Meteorological Office, Bracknell, Berkshire for supplying data used in this analysis.

\section{REFERENCES}

[1] Bulmer, M. (1975): The statistical analysis of density-dependence. - Biometrics 31: 901911.

[2] Common Bird Census. Breeding Birds in the Wider Countryside. British Trust for Ornithology and Joint Nature Conservation Committee. - Available at: http://www.bto.org/survey/cbc.htm. Accessed 12 November 2007.

[3] Marchant, J.H., Hudson, R., Carter, S.P., Whittington, P. (1990): Population trends in British Breeding Birds. - Herts ISBN 0-9037 93-03-2.

[4] Williamson, K. (1964): Bird census in woodland. - Bird Study 11: 1-22.

[5] Stata Corporation. Stata Statistical Software: release 6. College Station, Texas. - Stata Press.

[6] Newton, I., Rothery, L., Dale, L.C. (1998): Density-dependence in the bird populations of an oak wood over 22 years - Ibis 140: 131-136.

[7] Krebs, J.R. (1970): Regulation of numbers in the Great Tit (Aves: Passerformes). - J. Zool. Lond. 162: 317-333.

[8] Greenwood, J.J.D., Baillie, S.R. (1991): Effects of density-dependence and weather on population changes of English passerines using a non-experimental paradigm. - Ibis 133: 121-133.

[9] Pan-European Common Bird Monitoring (PECBM). (2007): Trends in common birds in Europe, 2007 update. European Bird Census Council. - Available at: http://www.ebcc.info/index.php?ID=148. Accessed 14 November 2007.

[10] Peach, W., du Fen, C., McMeeking, J. (1995): Site tenacity and survival rates of Wrens Troglodytes troglodytes and Treecreepers Certhia familiaris in a Nottinghamshire wood. - Ibis 137: 497-507.

[11] Orell, M. (1989): Population fluctuations and survival of Great Tits Parus major dependent on food supplied by man in winter - Ibis 131: 112-127.

[12] Siriwardena, G.M., Baillie, S.R., Wilson, J.D. (1998): Variation in the survival rates of British farmland passerines with respect to their population trends. - Bird Study 45: 276292. 